\title{
Desigualdades de género en ciencia, el caso de las científicas de la UAEMéx
}

\author{
Ana Karen Sánchez Jasso' \\ Elva Rivera Gómez ${ }^{2}$ \\ Juan Jesús Velasco Orozco3 ${ }^{3}$
}

Recepción: 28 de junio de 2016 / Aprobación: 7 de agosto de 2016

\section{Resumen}

Históricamente en el ámbito científico, las mujeres han pasado de la exclusión a la segregación. Diversos han sido los mecanismos implementados a fin de conseguir la igual distribución de género en ciencia y tecnología, si bien hay avances en cuanto al acceso a la educación, sigue siendo poca su presencia en puestos de reconocimiento y toma de decisiones. El objetivo de esta investigación es conocer las condiciones en las que se desarrollan y consolidan en el ámbito científico las y los académicos de la Universidad Autónoma del Estado de México (UAEMéx) pertenecientes al Sistema Nacional de Investigadores (SNI) en México, mediante el análisis estadístico institucional y el enfoque de la antropología de la experiencia basada en vivencias personales y laborales. Con los resultados obtenidos se puede concluir que la persistencia de inequidades en ciencia se relaciona directamente con la transmisión y reproducción de los estereotipos de género.

\section{Palabras clave}

Desigualdades; ciencia; estereotipos de género; UAEMéx; México

\section{Abstract}

Historically, women in Science have gone from exclusion to segregation. Various mechanisms have been implemented in order to achieve equal gender distribution in science and technology, but, although there has been progress in equal access to education, women still get little recognition and are poorly represented in decision-making positions. The goal of this research is to present through institutional documentary analysis, and the focus of anthropology of experience, based on personal and working experiences, the

1 Mexicana. Licenciada en Antropología Social, por la Universidad Autónoma del Estado de México. Becaria en el Centro de Investigación, Capacitación, Estudios y Proyectos Especializados en Género (CICEPEG), México. Correo electrónico: karens.jasso@gmail.com

2 Mexicana. Doctora en Historia y Estudios Regionales por la Universidad Veracruzana, México. Profesora-Investigadora de tiempo completo. Coordinadora del Colegio de Historia de la Facultad de Filosofía y Letras de la Benemérita Universidad Autónoma de Puebla. Correo electrónico: elva.rivera@gmail.com

3 Mexicano. Doctor en Antropología Social por la Universidad Iberoamericana, México. Profesor-Investigador de tiempo completo de la Facultad de Antropología, Universidad Autónoma del Estado de México. Correo electrónico: jujevo@gmail.com 
conditions under which the academics develop and position themselves in the scientific field of high profile researchers at the Autonomous University of the State of Mexico. Based on the results, it can be concluded that the persistence of inequity in science is directly related to the transmission and reproduction of gender stereotypes.

\section{Key words}

Inequalities; science; gender stereotypes; UAEMex; Mexico

\section{Resumo}

Historicamente, no campo científico, as mulheres passaram de exclusão à segregação. Vários mecanismos têm sido implementados, a fim de obter uma distribuição igual de gênero em ciência e tecnologia, embora haja progressos no acesso à educação, permanece baixa a sua presença em posições de reconhecimento e tomada de decisão. O objetivo desta pesquisa é compreender as condições em que se desenvolvem e consolidam as acadêmicas e os acadêmicos no campo científico da Universidade Autônoma do Estado do México (UAMex), pertencentes ao Sistema Nacional de Investigadores (SNI, acrônimo em espanhol) no México, através de análise estatística institucional e abordagem da antropologia da experiência com base em experiências pessoais e profissionais. Com os resultados obtidos pode-se concluir que a persistência de desigualdades na ciência está diretamente relacionada com a transmissão e reprodução de estereótipos de género.

\section{Palavras chave}

Desigualdade; ciência; estereótipos de género; UAEMex, México

\section{Introducción}

La ciencia es una de las estructuras sociales más importantes a partir de la cual se fundamenta y construye una realidad de nuestra existencia en el mundo, ya que influye de manera determinante, en el desarrollo y bienestar social, definiendo y redefiniendo procesos históricos, sistemas económicos y estructuras sociales desde hace más de 500 años (Pérez en Blázquez, 2014, p.13). Sin embargo, la ciencia no siempre ha estado al alcance de la sociedad, posee, en sus inicios, rasgos de cierta autonomía política consistente en dejar en manos de los "especialistas" su desarrollo y gestión. Empero la importancia de la generación y aplicación del conocimiento científico y tecnológico para la mejora de la calidad de vida de la sociedad y para el desarrollo económico de los países llevó a los estados occidentales industrializados a plantearse la necesidad de implementar una política científica (Pérez en Blázquez, 2014), que abonará en la construcción de una ciencia moderna inclusiva de la sociedad, lo que supuso entre otras cosas, volver la mirada a un problema social histórico pero aún presente: la discriminación contra las mujeres en los 84 sistemas de ciencia y tecnología. 
Históricamente en el ámbito científico, las mujeres han pasado de la exclusión a la segregación. Diversos han sido los mecanismos y acciones llevados a cabo a fin de conseguir la estructuración de un sistema de ciencia basado en la igual distribución de género. Sin embargo, datos estadísticos recientes establecen que si bien se presentan algunos avances en cuanto al acceso de las mujeres a la educación, especialmente al nivel superior ${ }^{4}$, sigue siendo poca su presencia en puestos de toma de decisiones, asociaciones científicas y academias así como en los sistemas de estímulo y reconocimiento (UNESCO 2007; INMUJERES, 2014; SNI, 2011; Blázquez, 2014; Mendieta, 2015).

El Instituto de Estadísticas de la UNESCO (UIS por sus siglas en inglés) estima que del total de personas dedicadas a la ciencia en el mundo, solo el $27 \%$ son mujeres; sin embargo, algunas cifras revelan un panorama alentador, por ejemplo, en América Latina y el Caribe las científicas constituyen casi la mitad $-45 \%$, muy por encima del 33.9\% del promedio europeo-, incluso el UIS calcula que en países latinoamericanos como Venezuela y Uruguay, en América Latina, así como en Filipinas y Tailandia, en el sudeste de Asia, tienen más científicas que científicos; no obstante, en otros países la cantidad de científicas es menor, tal es el caso el caso de México y Chile, donde hay más de dos científicos varones por cada científica (Dickson \& Therese, 2011).

El reciente Informe Internacional sobre Ciencia, Tecnología y Género de la Unesco (2007) establece que la dimensión de género en Ciencia y Tecnología ha ido adquiriendo una importancia creciente, tornándose en un tema de actualidad en todo el mundo. En América Latina existen iniciativas importantes que buscan conocer y reconocer la situación de las mujeres en esta parte del mundo, tal es el caso de la creación de la Red Iberoamericana de Ciencia, Tecnología y Género (RICTYG), conformada por redes de nueve países a saber Argentina, Brasil, Colombia, Uruguay, Venezuela, Cuba, Guatemala, España y México.

La Red Mexicana como parte de la Red Iberoamericana establece entre sus objetivos básicos, el desarrollo de estudios e investigaciones tanto cuantitativas como cualitativas que lleven a una mejor comprensión de la dinámica entre ciencia y género (Red Mexicana de Ciencia, Tecnología y Género, 2015), así como establecer relaciones y comparación de lo que ocurre en los espacios formadores de personal de investigación, tales como institutos, centros de investigación, academias y por supuesto las universidades (Blázquez, 2014) con el fin de generar datos que conduzcan a contextualizar las condiciones en las que mujeres y hombres se desarrollan y posicionan en los sistemas de ciencia y tecnología.

4 Según datos del Sistema de Indicadores de Género del Instituto Nacional de las Mujeres México, (INMUJERES) en 2010 se observó una disminución de la brecha por sexo de la matrícula total a nivel licenciatura, con 50.5\% de matrícula masculina y 49.5\% matrícula femenina y las cifras para 2014 han variado poco, $50.4 \%$ matrícula masculina frente a un $49.6 \%$ matrícula femenina. 
El objetivo de esta investigación es conocer las condiciones en las que se desarrollan y consolidan en el ámbito científico una muestra de las y los académicos de la UAEMéx pertenecientes al SNI en México, mediante el análisis estadístico institucional y el enfoque de la antropología de la experiencia basada en vivencias personales y laborales.

Cuando se relaciona el género con la ciencia, desde el punto de vista de la epistemología feminista (Maffía, 2006) interesa sí, conocer el papel que juegan las mujeres como productoras de conocimiento, pero principalmente discutir los elementos, las prácticas culturales, sociales, institucionales e incluso metodológicas que el género imprime a los procesos de producción científica. Por tal razón, la relevancia de la presente investigación se fundamenta en la necesidad de recopilar y generar información sobre la dinámica entre la ciencia y el género en México; así como continuar con los esfuerzos y el camino ya comenzado por investigadoras e investigadores de la UAEMéx ${ }^{5}$ y de otras Universidades del país que promueven una política educativa basada en justas y equitativas condiciones de ingreso, desarrollo, consolidación y reconocimiento en el ámbito científico.

El método empleado en esta investigación social se basó en el análisis de los indicadores institucionales, referentes al número total de miembros pertenecientes al SNI y al número total por sexo, presentados en la Agenda Estadística 2014 (ciclo agosto 2014-julio 2015) de la UAMéx, así como en el estudio de las experiencias laborales y personales de una muestra conformada por 14 investigadoras e investigadores con reconocimiento vigente del SNI, a través de la realización de entrevistas a profundidad.

El artículo está estructurado de la siguiente manera: en la primera parte se presenta una revisión general sobre la literatura internacional de los estudios relacionados con la ciencia, la tecnología y el género, con la finalidad de contar con un precedente sobre los avances y postulados que han girado en torno a esta temática de investigación. Posteriormente, se exponen los principales resultados obtenidos del análisis estadístico, así como de las narrativas de las y los investigadores. Por último, se presentan las reflexiones finales y una recomendación a la UAMéx, la cual busca contribuir con el empuje de una dinámica de ciencia-género universitaria caracterizada por la igualdad.

$5 \quad$ Para mayores referencias sobre estas investigaciones puede consultarse Hernández (2003); Vizcarra y Vélez (2007); Vélez Graciela; Vizcarra Ivonne; Vaca Norma, \& Díaz Guillermina (2011); López y Gálvez (2010) y González (2013). Cabe señalar que las conclusiones de estos trabajos evidencian que la diferencia numérica entre la matrícula del alumnado y profesorado no es significativa. En el ámbito del reconocimiento científico, las investigadoras universitarias aún ocupan lugares de menor jerarquía. 


\section{Ciencia, tecnología y género}

Históricamente el acceso a la vida académica-científica para las mujeres ha estado restringido como resultado de una cultura patriarcal que, basada en estereotipos de género, ha centralizado el conocimiento en la experiencia masculina. La limitación en el acceso al saber y al consiguiente poder que ello supone ha sido una de las prohibiciones más fuertes que la historia y la cultura patriarcal ha impuesto a las mujeres (Fernández, 2008). El patriarcado, como uno de los principales y más longevos sistemas de dominación, ha generado un modelo de construcción sociocultural basado en el principio de desigualdad "natural" entre los sexos. Esta visión, además sexista considera a las mujeres como seres irracionales, emocionales y pasivos en consecuencia, no dignas de confianza y aceptación para el desempeño de actividades consideradas racionales (masculinas), como es el caso del trabajo científico (Rivera, 2010). En este sentido, podemos apuntar que desde el origen de la ciencia, esta ha hecho de la experiencia masculina, la experiencia universal.

Los estudios feministas han puesto en discusión el poder patriarcal, así como los estudios de género han develado, en primer lugar, que la construcción social de la diferencia sexual excluyó a hombres y mujeres de los espacios privados y públicos respectivamente, de forma distinta, privilegiando el poder masculino (Rivera, 2012) y, en segundo lugar, que las mujeres han pasado de la exclusión a la segregación en el ámbito científico, estableciendo con esto la necesidad de encontrar y explicar por medio de qué mecanismos ocultos se perpetúa aún su ausencia en la actividad científico-tecnológica. Diana Maffía argumenta que los hallazgos epistemológicos más fuertes del feminismo se encuentran en la conexión que se ha hecho entre conocimiento y poder, en el sentido de que el reconocimiento de la legitimación de las pretensiones de conocimiento están íntimamente ligadas con redes de dominación y de exclusión (2006, p. 50).

Es decir, en la producción del conocimiento no hay una posición neutra del individuo, las y los científicos son sujetos atravesados por determinaciones sociales, históricas, temporales y espaciales, por un contexto social, que valora y legitima determinadas prácticas y saberes. María Ángeles Durán (citada por González, 2002), ha referido que el trabajo científico al estar inmerso en un contexto social, presenta al sexismo -manifestado hasta el día de hoy en la práctica científica- de maneras muy específicas, entre ellas, la selección de los temas de investigación, la selección de perspectivas teóricas, la elección de criterios de evaluación, el reconocimiento profesional y académico, y las normas y prácticas sociales de los colectivos creadores de ciencia o conocimiento especializados, concluyendo así que el sexismo está inmerso en todas y cada una de las etapas de la producción científica. 


\section{Aproximaciones teóricas al estudio de las mujeres en la ciencia}

Para fines de este trabajo de investigación, los elementos teóricos y conceptuales que se emplearán como marco de referencia para explicar las brechas de género, los mecanismos de exclusión, de segregación y la reproducción de prácticas culturales de los creadores de ciencia, que están imposibilitando una plena y justa consolidación científica de las investigadoras universitarias, provienen del enfoque sociocultural.

La escasa presencia de las mujeres en los sistemas de ciencia y tecnología es un fenómeno que ha sido calificado como persistente, progresivo y arraigado a nivel mundial. En la literatura internacional han sido tres los grandes marcos teóricos explicativos en los que se han clasificado las investigaciones y estudios que desde mediados del siglo pasado han emergido para ofrecer una respuesta a la poca y a veces nula participación de las mujeres en el ámbito científico: en primer lugar, se encuentra el enfoque biologicista, guiado en características individuales; en segundo lugar, el enfoque psicosocial y sociocultural centrado en aspectos del tipo colectivo; y, por último, aquel que cuestiona la epistemología de la ciencia y que ha puesto énfasis en sus aspectos estructurales y organizativos (Vázquez, 2015, p. 180).

El enfoque biologicista surgió a principios de la década de 1970, proponiendo que la elección de estudios y ocupaciones profesionales tenían un origen de carácter biológico. Este enfoque fue ampliamente cuestionado por los estudios feministas, principalmente por las limitaciones metodológicas y explicativas demostradas, ya que los resultados arrojados en torno a la brecha por género en la ejecución de habilidades y destrezas si se presentaba nunca resultaba significativa, además que restaban importancia tanto a las similitudes encontradas entre mujeres y hombres, así como a los casos en donde el rendimiento femenino era superior (Sagebiel \& Vázquez, 2010). Alternativas teóricas como las biologicistas proveyeron a la sociedad de una base científica sólida que permitió seguir considerando que los hombres tienen inherentemente mayor capacidad intelectual que las mujeres (González, 2002).

En la década de 1980, la evidencia empírica logró desacreditar el enfoque biologicista evidenciándolo como tradicionalista y esencialista, por lo que a partir de entonces la atención ya no se centró en características y diferencias individuales, sino del tipo colectivo, surgiendo el enfoque psicosocial y sociocultural. Este enfoque propone que la reproducción de los estereotipos de género aprendidos y transmitidos por generaciones a través de procesos de convivencia social, no solo adscriben características y roles diferenciados a hombres y mujeres, sino que definen sus esquemas de referencia, influyendo así en sus expectativas y comportamientos, y, en última, instancia reforzando 88 la continuidad de la segregación formativa y ocupacional, por tanto, esta rama 
de la literatura ha explorado el papel de los estereotipos de género, la presión y la influencia de los procesos de aprendizaje inicial y la socialización en el proceso de la construcción de la identidad de género (Suter, 2006, p. 97; Sagebiel \& Vázquez, 2010, p. 23).

El enfoque que cuestiona la epistemología de la ciencia se basa en el postulado que considera que si la respuesta anhelada de la segregación de las mujeres en el ámbito científico no refirió a un déficit biológico-individual, entonces el problema posiblemente radicaba en uno de la propia ciencia, con lo que los estudios desde este enfoque cuestionaron la organización, estructura, contenidos y prácticas de la investigación científica (Vázquez, 2015).

Con lo señalado anteriormente se apunta a que lejos de encontrar limitada esta perspectiva de cuestionamiento a la propia epistemología científica, en este proyecto de investigación se considera relacionada directamente con la perspectiva psicosocial y sociocultural, científica, ya que son los individuos en tanto seres sociales los que crean los principios y contenidos de la ciencia.

Uno de los conceptos propios del enfoque teórico psicosocial y sociocultural sobre el cual habrá que poner especial atención es el de género, que puede definirse como una construcción cultural que "denota toda la creación social de las ideas acerca de los roles apropiados para las mujeres y para los hombres" (Scott, 2008, p. 53).

Tomando como referencia que el género es una categoría de connotación cultural habría que entender las cualidades que confieren especificidad al concepto de cultura, lo que ayudará en última instancia a reforzar la idea propuesta por las autoras y el autor de este trabajo, sobre la pertinencia del enfoque teórico sociocultural para explicar las desigualdades de género en los sistemas de ciencia y tecnología.

El estudio y la investigación de la cultura humana, argumenta la antropóloga feminista Marta Lamas, "ha sido la línea rectora de la ciencia antropológica, motivo por el cual uno de los intereses ha sido, esclarecer hasta donde ciertas características y conductas humanas son aprendidas o si ya están en la naturaleza humana" (1986, p. 173). Los aportes principales de esta disciplina desde el feminismo, se han concentrado en concluir que la diferencia sexual, se ha convertido en desigualdad social y que son los hechos socioculturales los que han determinado la subordinación de las mujeres.

La cultura funciona para los individuos, en tanto miembros de una sociedad, como un esquema de percepción a través del cual observan, comprenden y explican su realidad. De la misma manera que constituye una guía de comportamientos y prácticas de cada individuo, fungiendo de cierta manera como un justificante, en cuanto que permite explicar, legitimar o deslegitimar sus acciones (Giménez, 2005). 
El proceso de transmisión cultural que se da a través de dos procesos sociales relevantes: la endoculturación y la socialización ${ }^{6}$, generan que niñas y niños aprendan no solo a comportarse de manera diferente, sino a ser tratados de formas distintas, ocasionando en última instancia la consolidación, reproducción, transmisión y, por tanto, la perpetuación de estereotipos de género (Vázquez, 2015). La cultura, como se revela hasta ahora, resulta una clave indispensable para descifrar la dinámica social, en este caso, la dinámica entre el género en tanto construcción cultural y la ciencia en tanto estructura social.

\section{El método para estudiar las desigualdades en la ciencia y tecnología desde la categoría género}

El método empleado en esta investigación social parte tanto del análisis textual como de las vivencias laborales y personales de las y los investigadores participantes.. En particular, se basa en la propuesta de la antropología de la experiencia que propone que al poner en circulación la vivencia, las experiencias y las subjetividades ayudarán a comprender más y mejor las formas culturales de la vida (Díaz, 1997). Por ello, contar con las voces de quienes viven reconocen, o no, y reproducen, o no, estos esquemas culturales resulta de vital importancia para este trabajo.

De igual manera, este estudio puede ubicarse dentro de las investigaciones con inspiración feminista, ya que se fundamenta en el empleo de las experiencias femeninas como un indicador de la realidad (Harding, 1998) y en el análisis de la relación entre los géneros (Bartra, 1998) con la finalidad de que los resultados puedan ser útiles para las mujeres y como efecto colateral, útiles para la reconstrucción de estas relaciones, volcándolas o haciéndolas más democráticas y equitativas.

Como antecedente es importante señalar que, en 2014, se revisaron los indicadores institucionales referentes al número total de miembros pertenecientes al SNI y al número total por sexo, presentados en la Agenda Estadística 2013 (ciclo agosto 2013-julio 2014) de la UAMéx, los cuales demostraron que el acceso para las mujeres a la educación superior ha ido en incremento (55.28\% del total para ese ciclo); sin embargo, prevalece la brecha de género en la medida en que la carrera científica exige más cualificación. En este caso, los niveles del SNI (35\% del total en el ciclo 2013-2014) y para el ciclo 2014-2015, las cosas no cambiaron mucho, de un total de 418 miembros del SNI, ellas representan el $36 \%$ del total. A partir de la obtención y análisis de estos resultados, se realizó durante los meses de julio a septiembre de 2015

$6 \quad$ La endoculturación entendida como el aprendizaje en el seno familiar -aprendizaje inicial- de los patrones culturales y la socialización como el consecuente reforzamiento a través de otras instituciones del medio social (Harris, 1995). 
la segunda parte del estudio sobre las trayectorias y experiencias de una muestra del personal científico de esta institución.

Así pues, se eligió la entrevista a profundidad como técnica, ya que esta desde el punto de vista antropológico es clave para profundizar en la subjetividad social (Robles, 2011), además, permite construir paso a paso la experiencia del Otro. El objetivo de la entrevista fue conocer, de manera general, la vida de las y los investigadores, es decir, tener un acercamiento a sus procesos de endoculturación y socialización y, de manera particular, centrar la atención en su desarrollo y consolidación como científicas y científicos. Se seleccionaron a 14 investigadoras e investigadores de la UAEMéx con reconocimiento vigente del SNI (Cuadro 1). La selección se fundamentó en la idea de poder abarcar, en lo posible, las percepciones de las y los universitarios por cada área del conocimiento, así como las apreciaciones y condiciones por cada nivel de reconocimiento.

\begin{tabular}{|c|c|c|c|c|c|}
\hline $\mathrm{N}^{\circ}$ & Sexo & Área de conocimiento & Edad & $\begin{array}{c}\text { Estado } \\
\text { civil }\end{array}$ & Nivel SNI \\
\hline 1 & $\mathrm{H}$ & C. Sociales y Administrativas & 74 & Soltero & III \\
\hline 2 & M & C. Sociales y Administrativas & 39 & Unión libre & Candidata \\
\hline 3 & M & Ciencias Agropecuarias & 48 & Casada & I \\
\hline 4 & $\mathrm{H}$ & C. Naturales y Exactas & 59 & Casado & $\|$ \\
\hline 5 & $\mathrm{H}$ & C. Naturales y Exactas & 59 & Divorciado & I \\
\hline 6 & M & Ciencias Agropecuarias & 55 & Casada & III \\
\hline 7 & M & Ciencias de la Salud & 51 & Divorciada & I \\
\hline 8 & $\mathrm{H}$ & Ciencias de la Salud & 40 & Casado & I \\
\hline 9 & M & Arte, Educación y Humanidades & 47 & Casada & I \\
\hline 10 & $\mathrm{H}$ & Arquitectura, Diseño y Urbanismo & 42 & Casado & I \\
\hline 11 & M & C. Naturales y Exactas & 46 & Casada & II \\
\hline 12 & M & Ingeniería y Tecnología & 48 & Casada & I \\
\hline 13 & M & Ingeniería y Tecnología & 52 & Casada & I \\
\hline 14 & $\mathrm{H}$ & Ingeniería y Tecnología & 49 & Casado & Candidato \\
\hline
\end{tabular}

Las entrevistas, en tanto se tuviera la autorización de las y los participantes, fueron grabadas. En seguida se transcribieron y analizaron para conocer la situación en la que están consolidando su trayectoria científicas y científicos dentro del claustro universitario. Los fragmentos seleccionados reservan la identidad de las personas entrevistadas y sus nombres son sustituidos por seudónimos. 


\section{Los sesgos y brechas de género en el Sistema Nacional de Investigadores de la Universidad Autónoma del Estado de México}

En este apartado presentamos los resultados de la investigación, que incluyen tanto los indicadores estadísticos tales como el número total de miembros pertenecientes al Sistema Nacional de Investigadores (SNI) y número total por sexo, presentados en la Agenda Estadística 2014 (ciclo agosto 2014-julio 2015) de la UAMéx, así como las experiencias laborales y personales de las y los investigadores participantes en las entrevistas a profundidad.

Hace más de 30 años, el SNI se ha enfocado en reconocer la labor de investigación de los científicos en México. Para las y los investigadores, la importancia de pertenecer al SNI radica sí en el incentivo económico, pero más aún en el reconocimiento y prestigio que este otorga a su trabajo, ya que en la actualidad formar parte de este es sinónimo de ser científico. Es por ello, que cada día más científicas y científicos buscan ser parte del sistema. Sin embargo, lograr consolidar una carrera científica productiva no resulta una actividad sencilla, pues para ser miembro del SNI es necesario realizar actividades de investigación de manera habitual (García, 2015, p. 30). Es decir, demanda tareas que requieren cierta disponibilidad de tiempo, más que como estudiante o académico.

Indicadores recientes del $\mathrm{SNl}^{7}$ revelan que si bien se ha presentado un relevante crecimiento por parte de las mujeres investigadoras, este no ha sido suficiente. De 1991 al 2000 las investigadoras pasaron de representar el 21\% al 28\% del total nacional (SNI-CONACYT, 2011, p. 6), a partir del año 2011 el porcentaje de mujeres en el SNI ha permanecido estable con un 34\% y, para principios del año 2015, con un total de 8244 investigadoras, constituye apenas el 36\% del total (Foro Consultivo Científico y Tecnológico AC, 2014, p. 6).

Para el caso de la UAMéx ${ }^{8}$, los resultados arrojaron que esta institución comparte rasgos en común a los presentados a nivel nacional. Podemos observar (Gráfico 1) que el porcentaje de investigadoras pertenecientes al SNI ha variado entre el 33\% y 35\%. En el año 2014, de un total de 418 miembros, 152 son mujeres lo que representa el $36 \%$ del total, coincidente con la media nacional. Con estos datos podemos constatar que la brecha por género en cuanto a investigación reconocida dentro de la universidad sigue siendo considerablemente significativa.

7 Cabe señalar que en la base de datos del SNI, los indicadores aparecen desagregados por sexo a partir de 1991. sino hasta el año 2010, por lo que se hará referencia a las cifras a partir de ese año. 


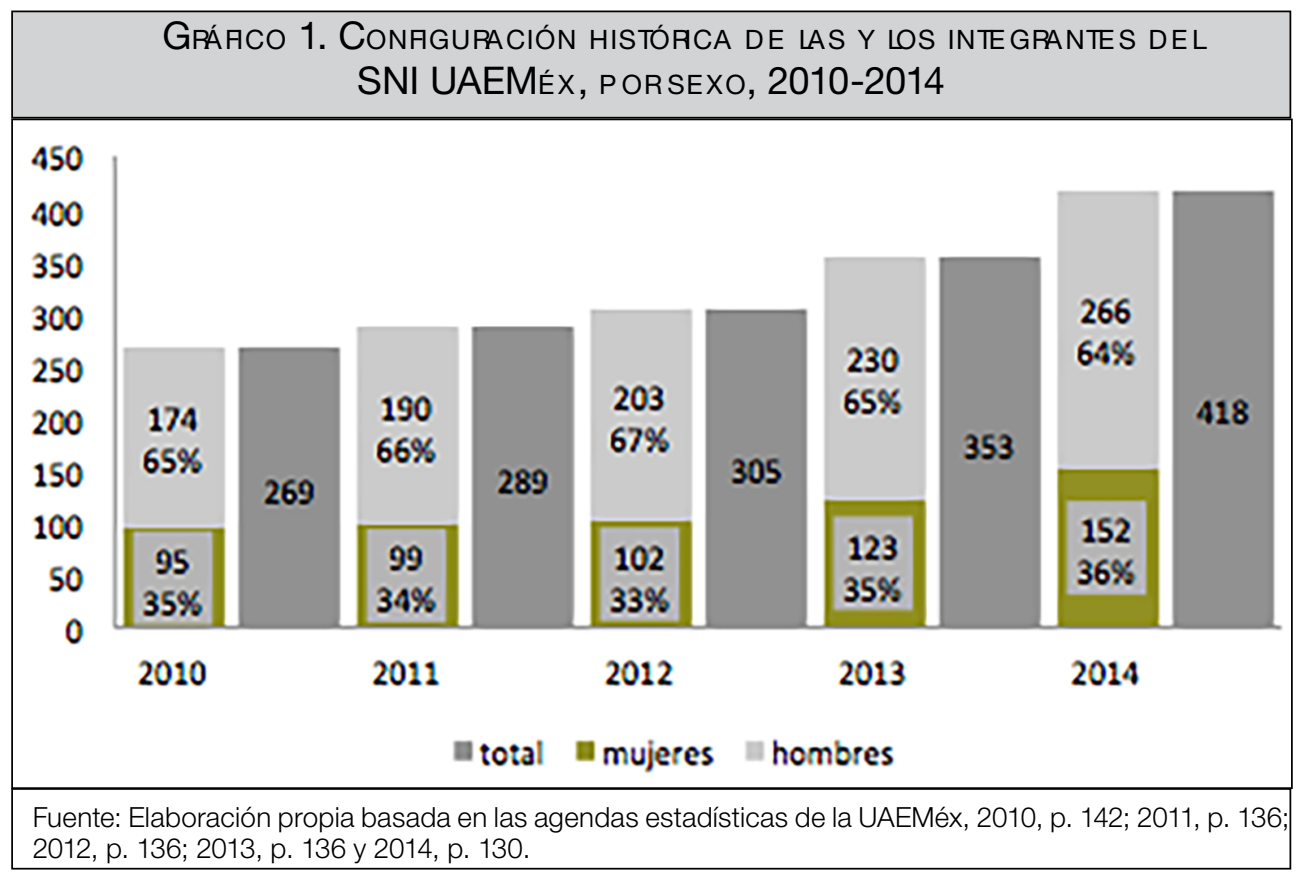

En el ciclo 2014-2015 la UAEMéx (corte hasta julio 2015) registró en el SNI 96 candidatas y candidatos a investigador nacional, de los cuales 35 son mujeres y 61 son hombres. En el nivel I hay 280, de los cuales 107 son investigadoras y 173 son investigadores; en el nivel II existen 38, de ellos 30 son hombres y solo 8 son mujeres, y únicamente hay 4 en el nivel III: 2 investigadoras y 2 investigadores.

Del total de hombres y mujeres, el porcentaje más alto de las mujeres en el SNI se ubica en el nivel I con el $71 \%$, mientras que el $23 \%$ de ellas son candidatas, el $5 \%$ están en el nivel II y, por último, el 1\% se sitúa en el nivel III. Estas cifras revelan que las investigadoras representan porcentajes más bajos en los niveles más altos de este sistema haciéndose visible la existencia de "techos de cristal"9 que impiden que ellas asciendan y logren la igualdad en los porcentajes ocupados por los varones.

A continuación se presentan las experiencias de las y los integrantes del SNI, participantes en este proyecto. La presentación de los fragmentos se clasificó en tres categorías que dan estructura a los datos obtenidos: educación y familia; persistencia de los estereotipos en la carrera científica; y mecanismos institucionales, de segregación y prácticas sexistas en la ciencia universitaria.

9 Mabel Burin (2008) propone que el concepto de "techo de cristal" hace referencia a las barreras invisibles con las que en determinados momentos de sus carreras, topan las mujeres, confiriéndoles una detención en su desarrollo profesional. 


\section{Educación y Familia}

Como se mencionó con anterioridad, el proceso endocultural tiene especial importancia en la reproducción de los estereotipos de género, es en casa donde se configuran los valores y comportamientos que se establecen socialmente. Niños y niñas, desde entonces, comienzan a generar representaciones de posibles realidades futuras. De esta manera, los progenitores o tutores transmiten, como agentes primarios de enseñanza, mensajes y etiquetas de género que dictan lo que una mujer femenina y un hombre masculino deben ser y por tanto hacer.

Por tal razón, es importante señalar que algunas investigaciones (Guiso, Monte, Sapienza \& Zingales, 2008) han demostrado que las niñas que viven en hogares marcados por igual trato de género tienden a hacer clasificaciones menos estereotipadas de las ocupaciones y se inclinan a seleccionar carreras no comunes con la representación social de su género. Para el caso un ejemplo:

Te hablo desde casa, somos tres mujeres y un hombre y todos recibíamos el mismo trato, mi papá me inculcó el gusto por los libros y a todos igual, nada más que nos gustaron más a dos de nosotros, entonces siempre eran los libros para mí, no me regalaban barbies, supongo que tiene que ver con todo esto. Entonces bueno la institución familiar a mí nunca me maltrató ni me dijo que tenía que comportarme de otra manera por ser mujer (Ana, Área de Educación y Humanidades, SNI I, 47 años, casada).

Las mujeres, como lo propone Marcela Lagarde (1990), comparten una condición de género, pero por razones políticas, históricas, culturales tienen diversas situaciones de género lo que, de maneras muy específicas, puede influir en la selección de una ocupación profesional.

\section{Persistencia de los estereotipos de género en la carrera científica}

La manera en que se decidió ahondar sobre los estereotipos en la ciencia durante las charlas con las y los investigadores, comenzó con un cuestionamiento crucial: ¿considera que las mujeres y los hombres tienen las mismas oportunidades para desempeñarse en el ámbito de la ciencia? De los 14 personas entrevistadas, cinco de seis investigadores dijeron que sí; y siete de las ocho investigadoras consideraron que las oportunidades son desiguales. Es verdad que cada vez encontramos a más mujeres presentes en actividades académico-científicas; sin embargo, en qué circunstancias las mujeres están ingresando a estas labores. Algunas reflexiones sobre el tema se presentan en el Cuadro 2. A partir de ellas, podemos argumentar que uno de los elementos

94 fundamentales que influye de manera importante en que las investigadoras 
consideren que tienen menos oportunidades para su desarrollo y consolidación está directamente vinculado con la reproducción de estereotipos sociales.

\section{Cuadro 2. ¿Considera que las M UJefes y los hom bFes TIENEN LAS M ISM AS OPORTUNIDADES PARA DESEM PEÑARSE EN ELÁM BITO DE LA CIENCIA?}

Fíjate que mucho tiempo creí que sí e En teoría sí, en la práctica nos cuesta incluso creo que en algunas áreas sí, mucho más. Un señor que aparece con pero los estereotipos sociales sí son corbata y con traje ya es un buen ingenieimportantes, yo no crecí con esos estereotipos, entonces no pensé que porque fuera mujer no podría tener las mismas oportunidades, pero te vas dando cuenta que terriblemente los estereotipos sí influyen (Amelia, área de Ciencias Sociales y Administrativas, SNI Candidata, 39 años, unión libre, 1 hijo (a) ).

Yo creo que hoy en día sí, creo que tiene las mismas oportunidades, se ha progresado todo que ahora creo que las mujeres van a comenzar a tener las cifras de su lado (Salvador, área de Ciencias de la Salud, SNI I, 40 años, casado, 2 hijos (as) ).

No, porque tenemos más oportunidades los hombres que las mujeres. ¿Cuál es la razón?, yo considero que la mujer llegó tarde, porque ahora ya cada vez va teniendo más oportunidades, pero antes no las tenía (Antonio, Área Ciencias Sociales y Administrativas, SNI III, 74 años, soltero).

ro, ya es un buen científico, ivamos tiene que serlo!, tu apareces como mujer con tu vestidito y es aquello de ¿qué me va a enseñar esta por dios? La verdad, vamos a ser sinceros, no te lo dicen porque se supone que ya somos todos muy correctos pero si te das cuenta, lo notas (Julieta, área de Ingeniería y Tecnología, SNI I, 48 años, casada, 1 hijo (a) ).

Sí, porque lo que te explicaba lo que puedo hacer yo, lo puedes hacer tú, el contar células, no hay limitación de género, o sea, es que quiera uno (Joaquín, área de Ciencias Naturales y Exactas, SNI I, 59 años, divorciado, 3 hijos (as) ).

No, claro que no, por lo menos las mujeres tenemos que pensar en nuestra edad reproductiva, los hombres no tienen que pensar en eso, pueden ser científicos jóvenes y nada de pensar en las mamilas y eso, podemos compartir, pero todavía no ha cambiado, nosotras estamos no dispersas pero ocupadas en la vida cotidiana, nuestro rendimiento productivo no es que sea de mala calidad, sino que es menor, ¿cuántos artículos crees que yo pueda hacer con tres hijos bebés, con respecto a un compañero que nada más llega a dormir, o que se ocupa de sí mismo nada más? (Sara, área de Ciencias Agropecuarias, SNI III, 55 años, casada, 3 hijos (as) ).

Fuente: Elaboración propia basada en el trabajo de campo julio-setiembre 2015.

Dentro de los estereotipos más comunes ligados a las mujeres se encuentra el de la maternidad, la mujer-madre como la denomina Marcela Lagarde en su famoso escrito sobre los cautiverios de las mujeres. La madre "es una institución histórica, fundamental en la reproducción de la cultura, es a través 
de la maternidad que la mujer es transmisora, defensora y custodia del orden imperante en la sociedad" (Lagarde, 1990, pp. 376-377). Ser madre en consecuencia es, según lo que marca el estereotipo, la realización del ser social de las mujeres.

Para muchas personas esta sigue siendo la imagen de la realidad, como para el caso de un investigador universitario, que considera que la función primordial de las mujeres está en la estructura de la base familiar:

Ya sé por dónde va esto, yo no sé por qué las mujeres quieren ser igual que los hombres. Como género, los hombres estamos mal. Para mí y siempre lo he dicho la mujer es más importante en el seno familiar. Antes estaban bien, con las mamás con las abuelitas, pues cada quien tiene sus roles porque siempre hemos sido iguales cada quien en su rol. Pero yo no sé por qué esa necedad de las mujeres por querer equipararse con el hombre. Desde hace 20 años que empezó todo esto, las mujeres ya no quieren estar en casa, ya no quieren tener hijos, la sociedad por eso está así, se está perdiendo la base familiar (Gillberto, área de Arquitectura y Diseño, SNI I, 42 años, casado, 1 hijo(a) ).

Las mujeres han sido y son educadas aún en muchas ocasiones para el desempeño de su rol dentro de una familia, al parecer este debería considerarse como su única ocupación, a este respecto el investigador comentó que para que las mujeres tengan éxito dentro de la investigación deben de asumir otro rol, dejar de ser mujeres y entrar al mundo de los hombres, esto es abstenerse de ser madres y, por lo tanto, reproduce la misoginia al negarle las capacidades racionales de las madres por el solo hecho de compartir la maternidad con la vida científica:

Si quiere ser una buena científica una propuesta sería que no tengan hijos o que tenga si quiere ser una científica mediocre. Las mujeres tienen otro rol muy diferente. La mujer debe asumir otro rol y dejar de ser mujeres si quieren ingresar a la carrera científica (Gillberto, área Arquitectura y Diseño, SNI I, 42 años, casado, 1 hijo(a) ).

Relacionado con la cualidad femenina de la maternidad está el postulado que vincula directamente el éxito profesional de las mujeres con la postergación o la anulación de esta, posponer la maternidad puede ser una estrategia para mantenerse competitivas en el ámbito laboral (Soto \& Flores, 2014). En esta muestra de población en específico cinco de las siete investigadoras tienen hijos, las dos restantes por decisión no ejercieron la maternidad. De las cinco madres de familia, cuatro de ellas postergaron su maternidad, dedicaron el tiempo biológico reproductivo a la investigación lo que les permitió poder desempeñarse y lograr cierto grado de consolidación en su carrera científica.

La maternidad conlleva en situaciones "ideales" la estructuración de una familia "nuclear", lo que da como resultado otro de los estereotipos comunes ligados a las mujeres, el cautiverio de la madre-esposa, el cual refiere que ellas además de ser madres y, por tanto, la base de la familia, en su papel va implícito el desempeño y cumplimiento de determinadas labores, entre las 96 que se incluyen las del tipo domésticas (Lagarde, 1990). 
Soledad Soto y Aurelia Flores al respecto señalan que "la maternidad y el funcionamiento del hogar se convierten en ataduras socioculturales que las mujeres llevan a cuestas a lo largo de su vida" (2014, p. 276) esto las orilla a cumplir con la consigna de ser todo al mismo tiempo, es decir, el tan sonado paradigma de la doble jornada laboral femenina. Ser madre y ser científica a la vez tiene un alto costo, pues se les duplica el trabajo y se les responsabiliza mucho más que a los hombres sobre el cuidado de la estructura familiar, en tanto que los hombres tienen la posibilidad de disponer de mayor tiempo para la realización de actividades científicas del tiempo que no dedican a las actividades domésticas (Zapata \& Pérez citado por Soto \& Flores, 2014).

En el Cuadro 3 se exponen algunas reflexiones de las y los investigadores sobre la conciliación de la vida personal con la vida científica-laboral, con estas se da cuenta que sigue sin existir una verdadera corresponsabilidad en el ámbito privado, los hombres como puede leerse toman una parte de las responsabilidades del hogar, es decir, apoyan circunstancialmente pero no se corresponsabilizan por completo, incluso los hombres como recurso para la sustitución de su responsabilidad en el hogar, buscan ayuda externa y es así como el papel de las mujeres en el ámbito privado se perpetúa. 


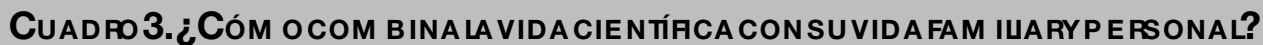

Pues mi esposa es ama de casa. Ella es el ama de casa ingeniero, arquitecto mamá, cocinera, lavandera, peluquera y todo lo que se ocurra. Y yo la mayor parte del tiempo la dedico a trabajar, excepto los fines de semana que es al revés, prácticamente el $90 \%$ a la casa, y si hay cosas que hacer del trabajo no las hago, lo compenso un poco (Guillermo, área de Ciencias Naturales y Exactas, SNI II, 59 años, casado, 2 hijos (as) ).

No pues en el trabajo hay que estar 8 horas. Hay días que estás más, días que estás menos dependiendo de lo que tienes que hacer y el resto es a la casa. En mi casa si yo hago la comida, él recoge los platos, como se hartó de recoger y lavar los platos se compró un lavavajillas eso ya fue problema de él, [es una] distribución, pero si midiéramos horas a la semana de quién hace más horas de la semana por las cuestiones de la casa soy yo ... terminas haciendo más cosas que tú pareja porque ellos tampoco han cambiado mucho de mentalidad (Luisa, área de Ingeniería y Tecnología, SNI I, 52 años, casada, 2 hijos (as) ).

El día tiene 25 horas y la semana 8 días, es compromiso, es distribución de actividades, son acuerdos y re-agendar acuerdos, tiene que ser así, tengo que programame cuando [mi hijo] ya se acostó, ya se durmió, entonces ya veo que más cosas hay que hacer en la parte de ciencia, así está distribuido y esos son acuerdos y comunicación porque si no pides ayuda piensan que lo puedes hacer todo (Margarita, área Ciencias Naturales y Exactas, SNI II, 46 años, casada, 1 hijo (a) ).
En casa básicamente mi esposa se encarga de las labores tiene quien le ayude pero ella se encarga. O sea, yo hago algunas cosas pero cada vez tengo menos tiempo. Los sábados solo trabajo de 9:00 am a 2:00 pm entonces la tarde ya me dedico a ellos, vamos a comer vamos al parque al centro comercial (Salvador, área de Ciencias de la Salud, SNI I, 40 años, casado, 2 hijos (as) ).

Después de mi hijo intento que el trabajo sea a todo lo que da en mi horario, mis ocho horas diarias, mis cuarenta horas semana, generalmente das un poquito más o te levantas un poquito más temprano o te vas un poquito más tarde. No me parece que haya un papá ausente, entonces una mamá ausente tampoco. [En casa] siendo muy necia con el marido, aquello de ok yo hago la comida, tú lavas los platos. En teoría lo tenemos los dos claro y buscamos llegar a esa corresponsabilidad. Ahora hay alguien que ayuda en casa pero eso lo paga él porque fue su idea, yo sí podía seguir haciéndolo (Julieta, área de Ingeniería y Tecnología, SNI I, 48 años, casada, 1 hijo (a) ).

Pues la mayor parte del tiempo, yo la paso en el trabajo, ya sea con los proyectos de investigación, con las clases, las tutorías, relativamente los fines de semana cuando se puede son para las cosas de la casa. Mi esposa es quien se ocupa de las labores en casa (Javier, área de Ingeniería y Tecnología, SNI candidato, 49 años, casado, 3 hijos (as) ).

Fuente: Elaboración propia basada en el trabajo de campo julio-setiembre 2015.

Sin embargo, resulta necesario acotar en este momento que la cultura patriarcal y los estereotipos de género, no solo representan una limitante para las mujeres, sino también para los hombres. Culturalmente ellos aprendieron a 
ser los únicos proveedores de un hogar, así que la mayor parte de su tiempo está distribuida en el ámbito público, lo que de alguna manera los aleja de una convivencia familiar, en contraste con las mujeres no está tan marcado su grado de "culpabilidad" ya que estar en casa no es su responsabilidad primaria; sin embargo, como lo comenta este investigador, también resulta difícil para ellos la lejanía familiar:

Tengo paternidad irresponsable, digo, con mi primer hijo estaba estudiando entonces lo llevaba al futbol, lo llevaba a todo, pero ya cuando llegué a trabajar se volvió complicado ... Pero bueno he atendido mi paternidad, ya haciendo investigación no he sido tan responsable, soy responsable digo cumplo con todas mis obligaciones, pero no he estado tanto como a lo mejor me hubiera gustado (Guillermo, área de Ciencias Agropecuarias, SNI II, 59 años, casado, 2 hijos (as) ).

La cultura patriarcal confronta a las mujeres a sentir culpa por no cumplir con los papeles asignados históricamente, es decir, con el cuidado de los "otros" como parte del "deber ser" de lo femenino. De tal forma que, en algunos casos la díada trabajo-maternidad implica sentir "culpa" por no cumplir con los mandatos de género en la familia o también privilegiar el cuidado de esta y renunciar al ascenso laboral. Al respecto Soledad Soto y Aurelia Flores señalan "que las mujeres al intentar conciliar la maternidad y la ciencia, viven consecuencias en el ámbito emocional y profesional” (2015, p. 277). La primera se refiere a la posibilidad de experimentar algún sentimiento de "culpa" por parte de ellas por quitar tiempo a su familia; la segunda implica los casos de renuncia a ascensos o la ocupación de cargos de mayor jerarquía y responsabilidad porque absorbe gran parte de su tiempo como responsables del hogar. En la UAEMéx, dos investigadoras, una de ellas jefa de familia y la otra madre de familia reflexionaron, respecto a la relación trabajo-maternidad, lo siguiente:

En la administración anterior era la mano derecha del director, o sea, se apoyaba mucho en mí, y ahí es cuando ya se complica el asunto de la familia. En alguna ocasión alguien me invitó a irme a rectoría a formar parte del equipo de la Secretaría de Investigación, y nada más de pensarlo ... dices ¡chin mano! si me voy a rectoría, los de rectoría terminan a las ocho o nueve de la noche ¿qué hago con mis hijos? Entonces de alguna manera pues sí te impide, pero te impide porque decides que te impida a final de cuentas, porque los hijos igual crecen, igual encuentras a alguien que te ayude y lo haga, pero a mí me gusta estar con mis hijos (Beatriz, área de Ciencias de la Salud, SNI I, 51 años, divorciada, 3 hijos(as) ).

En el caso de cuando a mí me invitan a la Dirección de Estudios Avanzados, haciendo remembranza estaba casada pero no tenía hijos, entonces las reuniones con el coordinador de investigación tenían que ser a las ocho y media de la noche y pues ese es un esfuerzo extra, y aprendí mucho, me sirvió mucho, pero pensándolo ahora yo ya no podría hacerlo por mil razones y la más importante mi hijo (Margarita, área de Ciencias Naturales y Exactas, SNI II, 46 años, casada, 1 hijo (a)).

También se identificaron algunas transformaciones en la dinámica familiar, en donde la pareja comparte las responsabilidades en el espacio doméstico. 
Esta forma de trabajo colaborativo ha beneficiado el desarrollo de algunas mujeres científicas. El caso específico de una de ellas, que hoy día es una de las investigadoras más reconocidas en la Universidad y que el prestigio de sus contribuciones científicas la han hecho acreedora a uno de los reconocimientos más altos en el SNI:

En casa todo es, ambos "mita y mita", michas todo. A mí me gusta mucho cocinar, entonces prefiero la comida y a mi esposo le gusta lavar los trastes, algo raro. Él siempre lava la ropa, le fascina todo lo que es agua, y a mí me gusta más lo otro, sacudir, organizar cajones, todo eso ... [Mi esposo] la otra parte participa de la misma manera, y si su trabajo se lo permite puede hacer un poquito más de lo que yo puedo hacer en el hogar, perfecto sin revanchas. No se mide el poder a partir de quien gana más, distribuimos los poderes democráticamente, una distribución democrática igualitaria, equitativa dentro del hogar donde nadie se sienta injusto ni dependiente, ni los padres ni los hijos (Sara, área de Ciencias Agropecuarias, SNI III, 55 años, casada, 3 hijos (as) ).

La corresponsabilidad en los asuntos domésticos juega un papel importante para la construcción de relaciones más democráticas en la pareja y familiares al interior del hogar y promover mejores condiciones en el desempeño de las mujeres en el mundo laboral. Hasta ahora las políticas públicas se han diseñado pensando en la incorporación de las mujeres al mundo laboral sin transformar la cultura masculina desde un enfoque de género. Por esta razón, las resistencias patriarcales se manifiestan tanto en el ámbito de lo doméstico como en el laboral.

Por otra parte, es importante señalar que en ciertas áreas del conocimiento prevalecen estereotipos, principalmente en las ingenierías o las ciencias exactas. Aún se piensa que las niñas (según dicta el estereotipo) no son tan buenas como los niños en matemáticas (Hill, Corbett \& Rose, 2010). Los aportes científicos de las mujeres en estas áreas han demostrado su capacidad intelectual; sin embargo, para ser reconocidas y escuchadas se han tenido que enfrentar a un persistente sistema patriarcal. A pesar de demostrar sus capacidades como líderes de investigación o elaborado propuestas en reuniones académicas, la cultura patriarcal mexicana en algunas ocasiones las ignora, las invisibiliza. A este respecto una investigadora comentó:

Los estereotipos son muy marcados aquí en México y más en carreras de Tecnología. Porque yo a veces he ido con compañeros a alguna oficina de gobierno o alguna institución, y al momento de hablar del tema y aunque yo fuera la responsable del proyecto, al final el ingeniero hablaba con el ingeniero, no hablaba conmigo, debía suponer que yo era la secretaria o la ayudante o yo que sé. Entonces aquí los estereotipos son muy marcados y aparte si te pones en un plan de luchadora y eso, entonces eres peor mirada. Y aquí en la universidad se sigue viendo de esa misma manera de que "ah ponen a mujeres porque hay que cubrir la cuota". Muchas veces uno se ve en unas circunstancias que no puedes creer. Por ejemplo, en reuniones me ha pasado que yo opino algo y ni caso, con diferentes palabras un hombre lo dice y a él le hacen caso, entonces te preguntas 
¿habré explicado mal, no se enteraron de lo que dije, no me escucharon? Pero si dijo lo mismo que yo ¿por qué a él le hicieron caso y a mí no? (Luisa, área de Ingeniería y Tecnología, SNI I, 52 años, casada, 2 hijos (as) ).

Susana Vázquez Cupeiro (2015) argumentó que los estereotipos de género no solo adscriben características sino que también tienen cierto carácter prescriptivo, es decir, partiendo de este supuesto, se puede proponer que mujeres y hombres tenderán a seleccionar estudios y ocupaciones profesionales que se adecuen de la mejor manera a la representación social de su rol. En este sentido encontramos la percepción de la investigadora del área de Ciencias Agropecuarias:

Cuando yo decidí estudiar [una carrera universitaria], me enfrenté al asunto de que no querían que estudiara ya que la disciplina que elegí se visualizaba como una carrera eminentemente masculina. [Después] Comencé a trabajar ... y la discriminación más fuerte la sentí por colegas, por compañeros. Cuando empecé yo a trabajar aquí en la universidad me sentí discriminada y que no se creía en mí ... (Josefina, área Ciencias Agropecuarias, SNI I, 48, casada).

Las desigualdades de género se presentan como un fenómeno persistente y arraigado. Estas reflexiones en torno a las diferentes maneras en las que aún se expresan, revelan la importancia de los cánones socioculturales que siguen funcionando como un agente disparador de la discriminación y segregación no solo en el ámbito científico, sino en todos los aspectos de vida de las mujeres e incluso de los propios hombres.

\section{Mecanismos institucionales, mecanismos de segregación y prácticas sexistas en la ciencia universitaria}

La historia ha revelado cómo las oportunidades de las mujeres han variado con el tiempo y con las barreras estructurales e institucionales existentes desde el nacimiento de la ciencia moderna (González \& Sedeño, 2002, párr. 23). Hoy día la discriminación por razones de sexo ya no se presenta de un modo explícito; sin embargo, en la estructura organizacional-institucional de los sistemas de ciencia y tecnología, se exhiben mecanismos implícitos de segregación y prácticas sexistas; en este entendido, se afirma que la ciencia androcéntrica y sexista ha promovido mecanismos más sutiles que contribuyen a legitimar la segregación de la mujer.

Los estereotipos de género creados en cada cultura a lo largo de la historia han permitido que en la ciencia se legitimen prácticas sexistas. A pesar de los avances, aún prevalecen ciertas prácticas que imposibilitan el desarrollo pleno de las mujeres en la vida profesional y, en especial, en la investigación. Por ejemplo, están presentes estrategias y barreras sexistas y misóginas de quienes dirigen las instituciones. Sus prácticas impiden que 
las mujeres -que no se subordinan a los mandatos de género- demuestren sus capacidades intelectuales.

Por ello, es de suma importancia visibilizar y analizar estas experiencias en las académicas de alto perfil en la universidad, pues coadyuva a valorar que las políticas de transversalización de la perspectiva de género en la universidad no han incidido del todo a transformar la cultura patriarcal en prácticas laborales incluyentes que reconozcan el trabajo individual y colectivo de las mujeres en los grupos de investigación. Tal es el caso de la transformación de categorías laborales, a pesar de obtener el grado correspondiente y contribuir al desarrollo científico de la comunidad y de la universidad. Citamos el siguiente caso:

Oiga Doctor, usted me dijo que cuando me titulara íbamos a ver lo de mi re-categorización. ¡Ah sí, sí! Siempre me daba largas y empezó él a ... Yo sentía que como para darme el avión, como para que yo viera que sí estaba interesado. Me decía: "Háganos una carta, dirijala al rector y póngale todo esto". Entonces la hice una vez. Y después de que la hice, me puse a leer el reglamento y me puse a ver, a averiguar y, pues ahí dice: que te tiene que proponer el coordinador. Y entonces, yo empecé a decirle: oiga doctor, ahí dice que usted es el que tienen que proponerme, hacer la solicitud de la promoción, o del examen de promoción o lo que usted quiera pero usted tiene que hacerlo. Y me dijo -vamos a hacerlo así ahorita a ver qué pasa-. Siempre me decía así, como una o dos veces al año, "haga usted la carta, así vamos a hacerlo, hágala, hágala". Y yo la hacía porque decía pues va a ser peor que diga que ni siquiera ha hecho nada, entonces la hacía (Amelia, área de Ciencias Sociales y Administrativas, SNI candidata, 39 años, unión libre, 1 hijo (a) ).10

La investigación que se desarrolla actualmente en las universidades obliga a trabajar en dos trayectorias académicas: individual (Programa de Mejoramiento del Profesorado - perfil PROMEP- y SNI) y colectiva, a través de los llamados Cuerpos Académicos o proyectos colectivos de grupos y redes de investigación. Estas nuevas prácticas de investigación científica han conducido a una competencia individual entre el profesorado adscrito a las universidades y ha impedido en algunos casos la colaboración colectiva y el reconocimiento de sus propios integrantes, en especial de las mujeres en los liderazgos de investigación, tanto individual como colectiva; como ejemplo, tenemos la siguiente narrativa de la investigadora:

Él era siempre el líder de los proyectos y nosotros pues sus achichincles. Siempre me hizo esa parte, lea la convocatoria. "Vamos a meter proyectos. Yo creo que ahora usted ya puede tener proyecto". Me emocionaba hacía mi proyecto, y le decía -Doctor ya está mi proyecto, y me decía- "Ya la mandamos" eso me lo hizo como dos o tres veces. Lo otro que me hacía era, me decía vamos a meter dos, uno usted y otro yo, algo se enojaba se empleitaba y nada. Yo no creo que

10 Después de aproximadamente dos años, la investigadora obtuvo la re-categorización, gracias a todas las cartas que envió al rector y por méritos personales. 
sea en toda la universidad, pero a mí me tocó (Amelia, área de Ciencias Sociales y Administrativas, SNI candidata, 39 años, unión libre, 1 hijo(a) ).

Ciertos mecanismos institucionales influyen para que la presencia de las mujeres científicas sea poco visible. Por ejemplo, en las políticas del SNI, la obtención del reconocimiento y los estímulos están relacionados directamente con la productividad científica, de esta manera la permanencia en el sistema y el ascenso de un nivel a otro implica una constante evaluación, la cual se realiza por comités integrados por la comunidad científica. En estos comités, según los estudios de Soto y Flores, se registra apenas un 20\% de participación de mujeres (2015, p. 279), lo que por razones claras ocasiona la reproducción de un modelo tradicionalista masculino. Uno de los investigadores reconoció que las mujeres evaluadoras son menos en los comités del SNI:

Hombres y mujeres no tenemos las mismas oportunidades. Por ejemplo, fui miembro de la comisión dictaminadora del Sistema Nacional de Investigadores, éramos 14 y mujeres eran apenas 4, o sea que ahí se ve el peso de que hay más investigadores que investigadoras ... ¿Cómo explicamos eso? (Antonio, área de Ciencias Administrativas y Sociales, SNI III, 74 años, soltero).

Las jerarquías de poder patriarcal en la división sexual del trabajo científico se manifiesta en la distribución de responsabilidades, los relacionados a la toma de decisiones (hombres) y los de orden administrativo (mujeres). Aspecto que amerita una investigación más profunda para conocer los alcances de las políticas de empoderamiento femenino en el área científica no solo a nivel nacional, sino en cada una de las universidades y centros científicos. En el caso de la UAEMéx identificamos que esta división sexual del trabajo científico está presente y se "visibiliza" en la medida en que se comparte y reflexiona entre las mujeres participantes de las comisiones académicas de posgrado:

Estamos en el área de posgrado. Vamos a una reunión de coordinadores de posgrado y mira por dónde el $90 \%$ somos mujeres. Dices ¿por qué en estas reuniones si somos el 90\% de mujeres y en las reuniones de secretarios por lo mucho hay una? Entonces platicamos entre nosotras, y resulta que sencillamente "ellos piensan que como mujeres somos ordenadas, metódicas, que nos gusta poner las cosas en su sitio y esas cosas, entonces como todo eso de los papeleos, estadísticas, tablitas, rellenar documentos a ellas se les da, entonces están pensando en nosotras como las secretarias de toda la vida". Y si no fíjate (busca la relación de coordinadores de posgrados) y verás que más de la mitad somos mujeres, porque nos asignaron el papel de secretarias, no porque seas una coordinadora de posgrado que tomes decisiones, sino que organiza papeles (Luisa, área Ingeniería y Tecnología, SIN I, 52 años, casada, 2 hijos (as) ).

El sistema de evaluación que prevalece en las universidades ha clasificado al profesorado a partir de los reconocimientos: grado máximo de estudios, perfil PROMEP, nivel de Cuerpo Académico, nivel del SNI, con lo cual se han reafirmado no solo nuevos estándares, sino lo que denominamos "clases o segmentos académicos universitarios" que han conducido a la estratificación de niveles, entre el de licenciatura y el de posgrado; entre quienes cuentan con 
todos los indicadores "las estrellas" de la evaluación académica; quiénes aspiran a llegar a la cúspide de la carrera científica; y quiénes se resisten a ingresar a los parámetros de la evaluación académica. A esta competencia hay que sumarle las jerarquías y prácticas sexistas patriarcales, por lo tanto, esto conduce a la discriminación de las élites académicas, donde las mujeres en algunas áreas son mayoría. Pero en los puestos de toma decisiones no logran alcanzar las direcciones; o bien en áreas de conocimiento altamente masculinizadas ellas encuentran más barreras para demostrar sus capacidades intelectuales.

Lo expuesto con anterioridad pone de manifiesto que los estereotipos sociales imponen a las mujeres que decidieron optar por una carrera científica, luchar día a día para lograr ser reconocidas en el sistema de ciencia interno universitario y externo ante el Consejo Nacional de Ciencia y Tecnología (CONACYT), donde aún prevalece una estructura androcéntrica que no pondera las relaciones de género en la evaluación científica de sus integrantes e impide que más mujeres ingresen al sistema científico, y que sus aportes contribuyan a la transformación de todas las áreas de conocimiento.

\section{Una recomendación para y desde la Universidad}

Parte esencial de los estudios con perspectiva de género, es no solo contribuir con análisis críticos, sino que a partir de estos, se puedan generar propuestas y alternativas que contribuyan con la mejora de las condiciones de las mujeres (y de los hombres) en los ámbitos tanto públicos como privados. En ese sentido, y a partir de la interpretación de la información obtenida, queremos presentar una recomendación a la UAMéx para promover un sistema científico incluyente y democrático que favorezca a transformar la percepción sobre las mujeres como sujetas de conocimiento en las diferentes áreas científicas con que cuenta la institución, contribuyendo de esta manera con la paulatina eliminación de las desigualdades presentadas en la práctica científica.

La recomendación se centra en el rescate y difusión de la historia de las mujeres científicas destacadas de la UAEMéx, a través de la compilación de sus esfuerzos, sus logros, sus aportaciones, pero también sus subjetividades, con el objetivo de generar nuevas imágenes de las mujeres como productoras de conocimiento (sin que esto entre en la etiqueta conservadora y sexista de "historia de grandes hombres" cambiado por "historia de grandes mujeres", género biográfico conservador como lo clasifica Diana Maffía). No se pretende promover estas historias como una evidencia de que no hay barreras $y$ que si las mujeres se esfuerzan lo suficiente pueden lograr el reconocimiento, sino como oportunidad de examinar el papel y el destino de las y los sujetos creadores (as) de conocimiento científico en el marco de una ciencia moderna estructurada bajo principios propiamente masculinos.

La Universidad como un espacio de formación tiene como compromiso social y político sumarse a los esfuerzos en la lucha rpo la eliminación de las desigualda- 
des por razón de sexo, por ello, la propuesta tiene como punto de partida una recomendación para la Universidad, pero tiene la intención de poder generar desde el ámbito institucional una influencia en la vida privada, ya que como advertimos, las inequidades en género tienen una base cultural, por lo que es necesario buscar que las alternativas incidan en los medios de aprendizaje, reproducción y reforzamiento de estereotipos de género, en este caso las instituciones educativas en todos sus niveles (educación básica, media superior, superior).

De manera que la intención de esta propuesta es abarcar en lo posible tanto a universitarias (os), jóvenes, niños y niñas, a través de la difusión generalizada, con la intención de contribuir a través de la concientización y sensibilización, la generación de una nueva memoria colectiva capaz de crear en este grupo social nuevas imágenes de las mujeres en la ciencia (ámbito público) que produzcan como efecto colateral nuevas representaciones sobre su papel en el ámbito privado. Por qué no basta como dice Diana Maffía con generar acciones que incentiven la incorporación de más mujeres en las carreras científicas "agregue mujeres y revuelva", sino de contribuir con acciones que coadyuven a desdibujar los estereotipos de género que aún dan estructura a la ciencia moderna.

Al respecto de la importancia de la generación de nuevas representaciones simbólicas de las relaciones entre mujeres y hombres, Nattie Golubov (2012) propone que las imágenes estereotipadas de las mujeres que se producen y circulan en el medio social contribuyen a naturalizar la diferencia de los sexos, al tiempo que fomentan la discriminación, el sexismo y la opresión.

Es así como las imágenes se convierten en puntos de referencia comunes para los individuos, por esa razón inciden directamente en la conformación de las identidades, de la autopercepción y de la dignidad de las mujeres y de los hombres, la deconstrucción de estas imágenes hegemónicas puede incidir de manera directa en la disminución de las desigualdades por razón de sexo, las prácticas sexistas, los mecanismos de segregación y los sesgos epistemológicos presentados hasta hoy día en la actividad científica.

Esta recomendación se suma a los esfuerzos precursores de investigadoras universitarias, que hasta ahora han contribuido con estudios tanto cualitativos como cuantitativos que han revelado que hasta hoy siguen presentándose brechas de género significativas en el ámbito del reconocimiento científico. Se concluye que es importante establecer como política institucional el desarrollo de indicadores de género que permitan un diagnóstico más asertivo en relación con la participación de hombres y mujeres en las actividades sustantivas de la Universidad. Con el fin de contribuir con la eliminación de las desigualdades por género se han publicado libros tales como: Personal académico en la UAEM. Mujeres y hombres en cifras 2004-2006 (Vélez, Vizcarra, Vaca \& Díaz, 
2011) y Género y éxito científico en la Universidad Autónoma del Estado de México (Vizcarra \& Vélez, 2007).

Para el caso de las investigaciones de corte cualitativo están Autobiografía de Mujeres Universitarias, coordinado por Graciela Vélez Bautista e Ivonne Vizcarra Bordi (2005) y Mujeres universitarias profesionales de la Química mexicana del siglo XX de Elena González (2013) que han centrado su atención en presentar testimonios y experiencias de mujeres universitarias activas, con la intención de sensibilizar a las (los) universitarios en torno de las desigualdades por sexo, así como de revalorizar y fortalecer la construcción de la identidad femenina universitaria.

Sin embargo, y a pesar de su variedad, los esfuerzos para promover la igualdad entre los sexos en la Universidad, señala la Dra. Guillermina Díaz ${ }^{11}$ (2011), han sido valiosos pero aún incipientes y se han centrado en la educación superior, por ello, la necesidad de continuar con acciones que promuevan cambios significativos no solo en el actuar de las y los científicos, sino también cambios sustanciales en la estructura androcéntrica de la ciencia.

\section{Consideraciones finales}

La ciencia ha estado marcada por un rostro masculino que, apoyada en enfoques biologicistas, ha privilegiado y legitimado dentro de sus principios estructurales la objetividad, la neutralidad y la universalidad, cualidades que se relacionan directamente con la representación social de la masculinidad, razón por la cual las mujeres "irracionales", "pasivas", "emocionales" no han tenido la oportunidad de desempeñarse en el ámbito de la producción científica en igualdad de condiciones que los hombres.

Las Universidades como espacios formadores de personal de investigación, siguen reproduciendo y legitimando de cierta manera el discurso patriarcal, ya que mujeres y hombres siguen ubicados y distribuidos en sitios con diferente valor y en el acceso y consolidación de su quehacer científico siguen estando presentes mecanismos implícitos de segregación, discriminación así como prácticas sexistas.

Una de las causas fundamentales que incide directamente en la persistencia de las inequidades en ciencia, es la transmisión y reproducción de los estereotipos de género, que han funcionado como marco de referencia conductual para los individuos en tanto miembros de una sociedad, desde esta lógica podemos apuntar que los cánones socioculturales funcionan como un agente disparador de las desigualdades de género tanto en el ámbito cien-

11 Para mayor información sobre los programas, proyectos y acciones desarrollados en la UAEMex, se puede consultar el texto de la Dra. Guillermina Díaz Pérez (2011) Avances para sensibilizar sobre la violencia de género en la Universidad Autónoma del Estado de México. 
tífico, como en todos y cada uno de los aspectos de vida de las mujeres e incluso de los hombres.

El estereotipo de mujer-madre y mujer-esposa llevan a que las investigadoras universitarias realicen una doble tarea, en tanto que el estereotipo de "únicos proveedores" conlleva a que gozan de mayor grado de permisividad social, lo cual les otorga mayor disponibilidad de tiempo para la realización exclusiva de actividades científicas. Por ello, el buscar alternativas que generen cambios en cuanto a la corresponsabilidad en los asuntos domésticos juega un papel importante para la construcción de relaciones más democráticas en la pareja y familiares al interior del hogar y promover mejores condiciones en el desempeño de las mujeres en el mundo laboral.

Dado lo anterior, concluimos que es de vital importancia comenzar a generar alternativas que busquen tener incidencia verdadera en el centro del problema, es decir, en la base cultural, generando una nueva memoria colectiva a través de la creación y reproducción de nuevas relaciones de género que se presenten como más incluyentes, democráticas y equitativas. La Universidad, en este sentido, como espacio de formación debe asumir un compromiso social y político en la lucha por la eliminación de las desigualdades por motivos de género.

\section{Referencias}

Bartra, Eli. (1998). Reflexiones metodológicas. En Eli Bartra (comp.), Debates en torno a una metodología feminista (pp. 141-155). México: Casa abierta al tiempo, Universidad Autónoma Metropolitana.

Blázquez Graf, Norma (Coord.). (2014). Evaluación Académica: Sesgos de Género. México: Centro de Investigaciones Interdisciplinarias en Ciencias y Humanidades, Universidad Nacional Autónoma de México.

Burin, Mabel. (2008). Las "fronteras de cristal" en la carrera laboral de las mujeres. Género, subjetividad y globalización. Anuario de Psicología, 39(1), 7586. Recuperado de http://www.redalyc.org/articulo.oa?id=97017401006

Díaz Cruz, Rodrigo. (1997). La vivencia en circulación. Una introducción a la antropología de la experiencia. Alteridades, 7(13), 5-15. Recuperado de http://tesiuami.uam. $\mathrm{mx} /$ revistasuam/alteridades/include/getdoc.php?id=197\&article=2\&mode=pdf

Díaz Pérez, Guillermina. (2011). Avances para sensibilizar sobre la violencia de género en la Universidad Autónoma del Estado de México. México. Recuperado de http://132.247.1.49/PAPIME306511/pdfs/PonenciaGuillerminaDiaz.pdf

Dickson, David \& Therese Jeanne. (2011). Mujeres en la ciencia: un recurso aún sin explotar. SciDev.Net Ediciones América Latina y el Caribe. Recuperado 
de http://www.scidev.net/america-latina/desarrollo-de-capacidades/editoriales/mujeres-en-la-ciencia-un-recurso-a-n-sin-explotar.html

Fernández Rius, Lourdes. (2008). Género, Ciencia ¿paridad es equidad? Arbor, 184(733), 817-826. Recuperado de http://arbor.revistas.csic.es/index.php/arbor/article/view/226/227

Foro Consultivo Científico y Tecnológico AC. (2014). Proceso de auscultación para proponer investigadores que podrían ser considerados para la renovación de las comisiones dictaminadoras del Sistema Nacional de Investigadores 2014. Recuperado de http://www.foroconsultivo.org.mx/asuntos/ academicos/sni2014/resultados_comisiones_dictaminadoras_2014.pdf

García Batiz, María Luisa. (2015). Reflexiones sobre los retos, permanencia y promoción en el SNI de las Investigadoras. En Angélica Mendieta (coord.), ¿Legitimidad o Reconocimiento? Las investigadoras del SNI. Retos y Propuestas (pp. 28-35). México: Ediciones La Biblioteca.

Giménez, Gilberto. (2005). Teoría y análisis de la cultura. México: Consejo Nacional para la Cultura y las Artes .

Golubov, Nattie. (2012). La crítica literaria feminista. Una introducción práctica. México: Facultad de Filosofía y Letras, Universidad Nacional Autónoma de México.

González García, Marta \& Pérez Sedeño, Eulalia. (2002). Ciencia, Tecnología y Género. Revista Iberoamericana de Ciencia, Tecnología, Sociedad e Innovación, (2). Recuperado de http://www.oei.es/revistactsi/numero2/varios2.htm

González Suárez, Mirta. (2002). Feminismo, academia y cambio social. Educación, 26(2), 169-183. Recuperado de http://www.redalyc.org/articulo. oa?id $=44026217$

González Vargas, Elena. (2013). Mujeres universitarias profesionales de la Química mexicana del siglo XX. México: Universidad Autónoma del Estado de México.

Guiso, Luigi; Monte, Ferdinando; Sapienza, Paola \& Zingales, Luigi. (2008). Culture, Gender and Math. Science, 320, 1164-1165. Recuperado de http:// www.kellogg.northwestern.edu/faculty/sapienza/htm/science.pdf

Harding, Sandra. (1998). ¿Existe un método feminista? En Eli Batra (comp.), Debates en torno a una metodología feminista (pp. 9-34). México: Casa abierta al tiempo, Universidad Autónoma Metropolitana.

Harris, Marvin. (1995). Antropología Cultural. Madrid: Alianza Editorial.

Hernández D., María. (2003). Las académicas universitarias mexicanas y su quehacer en la docencia, en la investigación y extensión; una aproxima- 
ción. Caso UAEM (Universidad Autónoma del Estado de México). México: Programa Universitario de Estudios de Género-Univesidad Autónoma del Estado de México.

Hill, Catherine; Corbette, Christianne \& Rose, Andresse. (2010). Why So Few? Women in Science, Technology, Engineering, and Mathematics. Washington: American Association of University Women Educational Foundation.

Instituto Nacional de las Mujeres. (2014). Sistema de Indicadores de Género. Educación. Recuperado de http://estadistica.inmujeres.gob.mx/formas/ tarjetas/Educacion.pdf

Lagarde, Marcela. (1990). Los cautiverios de las mujeres madresposas, monjas, putas, presas y locas. México: Universidad Nacional Autónoma de México.

Lamas, Marta. (1986). La antropología feminista y la categoría género. Nueva Antropología, 8(30), 173-198. Recuperado de http://www.redalyc.org/articulo.oa?id=15903009

López Suárez, Adolfo \& Pichardo Gálvez, Jorge. (2010). Trayectoria escolar y género en ingeniería civil, el caso de la UAEMéx. CIENCIA ergo sum, 17(1), 89-96. Recuperado de http://cienciaergosum.uaemex.mx/index.php/ergosum/article/view/972/710

Maffía, Diana. (2006). El vínculo crítico entre género y ciencia. Clepsydra, 5, 37-57. Recuperado de http://publica.webs.ull.es/upload/REV\%20CLEPSYDRA/05-2006/03\%20(Diana\%20Maff\%C3\%ADa).pdf

Mendieta Ramírez, Angélica (coord.). (2015). ¿Legitimidad o Reconocimiento? Las investigadoras del SNI. Retos y Propuestas. México: Ediciones La Biblioteca.

Rivera Gómez, Elva. (2010). De la manifestación al aula. Saberes, silencios e inequidades en la Universidad Autónoma de Puebla (1972-2001) (Tesis de Doctorado en Historia y Estudios Regionales). Universidad Veracruzana, Veracruz, México.

Rivera Gómez, Elva. (2012). De la Historia Universal del Hombre a la Historia de las masculinidades. El androcentrismo en los estudios históricos. La Manzana, (9). Recuperado de http://www.estudiosmasculinidades.buap. mx/num9/index.html

Red Mexicana de Ciencia, Tecnología y Género. (2015). Recuperado de http:// redmexciteg.org/

Robles, Bernardo. (2011). La entrevista en profundidad: una técnica útil dentro del campo antropofísico. Cuicuilco, 18(52), 39-49. Recuperado de http://www.scielo.org.mx/scielo.php?script=sci_arttext\&pid=S0185-16592011000300004 
Sagebiel, Felizitas \& Vázquez Cupeiro, Susana. (2010). Topic Report. Meta-analysis of gender and Science research. Stereotypes and identity. Recuperado de http://genderedinnovations.stanford.edu/images/TR3_Stereotypes.pdf

Scott, Joan. (2008). Género e Historia (Trad. C. Vilá). México: Fondo de Cultura Económica / Universidad Autónoma de la Ciudad de México.

Soto Ríos, Soledad \& Flores Hernández, Aurelia. (2014). Estrategias de conciliación de la vida familiar y científica en integrantes del SNI de la UATlaxcala. En Norma Blázquez (coord.), Evaluación Académica: Sesgos de Género (pp. 275-300). México: Centro de Investigaciones Interdisciplinarias en Ciencias y Humanidades, Universidad Nacional Autónoma de México.

SNI-CONACYT, Archivo Histórico. (2011). Estadísticas Básicas. Recuperado de http://www.conacyt.mx/images/conacyt/sni/archivo_historico/estadisticas/ Estadisticas_basicas_2011.pdf

Suter, Christian. (2006). Trends in gender segregation by field of work in higher education. En OECD, Women in Scientific Careers: Unleashing the potential (pp. 95104). París: Organisation for Economic Co-operation and Development OECD.

UNESCO. (2007). Ciencia, Tecnología y Género. Informe Internacional. Resumen. Uruguay: UNESCO.

Universidad Autónoma del Estado de México. (2014). Agenda Estadística 20142015. México.

Vázquez Cupeiro, Susana. (2015). Ciencia, estereotipos y género: una revisión de Ios marcos explicativos. Convergencia Revista de Ciencias Sociales, 22(68), 177-202. Recuperado de http://www.redalyc.org/articulo.oa?id=10536227007

Vélez, Graciela; Vizcarra, Ivonne; Baca, Norma, \& Díaz, Guillermina. (2001). Personal académico en la UAEM. Mujeres y hombres en cifras 2004-2006. México: Universidad Autónoma del Estado de México.

Vélez, Graciela \& Vizcarra Bordi. (Comps.). (2005). Autobiografías de Mujeres Universitarias. México: Universidad Autónoma del Estado de México.

Vizcarra Bordi, Ivonne \& Vélez, Graciela. (2007). Género y éxito científico en la Universidad Autónoma del Estado de México. Estudos Feministas, 15(3), 581-608. Recuperado de http://www.scielo.br/pdf/ref/v15n3/a05v15n3.pdf

Wacjman, Judy. (1991). Feminism confronts technology. Cambridge: Polity Press. 